\title{
Antecedents and Consequences of Work Engagement Among Nurses
}

\author{
Sanaz Sohrabizadeh ${ }^{1}$; Nasrin Sayfouri ${ }^{2, *}$ \\ ${ }^{1}$ Department of Health Services Management, School of Health Management and Information Sciences, Iran University of Medical Sciences, Tehran, IR Iran \\ ${ }^{2}$ Department of Foreign Languages, School of Health Management and Information Sciences, Iran University of Medical Sciences, Tehran, IR Iran \\ *Corresponding Author: Nasrin Sayfouri, Department of Foreign Languages, School of Health Management and Information Sciences, Iran University of Medical Sciences, Tehran, IR \\ Iran. Tel: +98-9123445585, Fax:+98-2144608143, E-mail: nasrinsayfouri@gmail.com
}

Received: November 24, 2013; Revised: January 21, 2014; Accepted: February 19, 2014

\begin{abstract}
Background: Engaged nurses have high levels of energy and are enthusiastic about their work which impacts quality of health care services. However, in the context of Iran, due to observed burnout, work engagement among nurses necessitates immediate exploration. Objectives: This investigation aimed to identify a suitable work engagement model in nursing profession in hospitals according to the hypothesized model and to determine antecedents and consequences related to work engagement among nurses.

Patients and Methods: In this cross-sectional study, a questionnaire was given to 279 randomly-selected nurses working in two general teaching hospitals of Shiraz University of Medical Sciences (Shiraz, Iran) to measure antecedents and consequences of work engagement using the Saks's (2005) model. Structural Equation Modeling was used to examine the model fitness.

Results: Two paths were added using LISREL software. The resulting model showed good fitness indices $\left(\chi^{2}=23.62, \mathrm{AGFI}=0.93, \mathrm{CFI}=0.97\right.$, RMSEA $=0.07)$ and all the coefficients of the paths were significant $(t \geq 2, t \leq-2)$. A significant correlation was found between work engagement and model variables.

Conclusions: Paying adequate attention to the antecedents of work engagement can enhance the quality of performance among nurses. Additionally, rewards, organizational and supervisory supports, and job characteristics should be taken into consideration to establish work engagement among nurses. Further researches are required to identify other probable antecedents and consequences of nursing work engagement, which might be related to specific cultural settings.
\end{abstract}

Keywords:Work Engagement; Nurses; Antecedents; Consequences; Hospitals

\section{Background}

Inside an organization, there has always been a tension between employee's needs and organizational demands. It was traditionally believed that employees are expected to adjust themselves to changing needs of organizations. However, the way organizations respond to ever-changing needs of employees has equally been considered crucial. It was previously supposed that financial aspect of job potentially provided the highest satisfaction for employees (1) while it has been shown that some employees had more attention to factors such as personal objectives, independence, satisfaction, intimate work relationship, and learning over financial impetus in their jobs (2). Positive Organizational Behavior (POB), originated from the concepts of positive psychology was emerged in response to these changes (3). POB is defined as 'the study and application of positively oriented human resource strengths and psychological capacities that can be measured, developed, and effectively managed for performance improvement in today's workplace' (4). One of the constructs of $\mathrm{POB}$ is work engagement defined as a positive, fulfilling, and work-related psychological state and has been characterized by vigor, dedication and absorption (5, 6). Engaged employees have high levels of energy, are enthusiastic about their work, and often fully immersed in their work (5).Engagement at work is considered as a potentially important workforce performance and the relationship between work engagement and performance-based organizational outcomes has already been supported $(7,8)$. Researchers continue to examine methods maximizing work engagement due to the strong relationships between work engagement and positive outcomes $(2,9)$. Scholars in organizational behavior demonstrated that engaged employees would be more likely to identify resources, work longer hours, and are more dedicated to their work. Additionally, work engagement is contagious and engaged employees can promote further engagement among their colleagues $(10,11)$. However, definitions and measurements of engagement, and more specifically, nurses' work engagement, are not fully comprehended yet universally (12). More theoretical and practical understanding of factors inducing and maintaining nurse engagement is therefore required to prioritize and implement interventions to improve nurses' performance, patients' outcomes and other core healthcare organizational outcomes (13). Burnout as a psychological syndrome manifested by fa-

Copyright ( ) 2014, Iranian Red Crescent Medical Journal. This is an open-access article distributed under the terms of the Creative Commons Attribution-NonCommercial 4.0 International License (http://creativecommons.org/licenses/by-nc/4.0/) which permits copy and redistribute the material just in noncommercial usages, provided the original work is properly cited. 
tigue, vulnerability, and inefficiency (14) has been detected worldwide. For instance, investigations showed that approximately 7-10\% of European nurses have severe or clinical burnout (15).This indicates that nursing, as a career is stressful with suffering, death, and grief on a daily basis. It seems essential in Iran to promote strategies to enhance work engagement, which can reduce burnout in nurses. Different studies performed in Iran reported relatively high burnout rates, such as teaching hospitals of Babol University of Medical Sciences (68.6\%) (16), Iran hospital in Tehran (44.5\%) (17), Rasht public hospitals (the mean value being $73.93 \pm 19.32)(18)$, hospitals in Mashhad (34\%) (19), teaching hospitals of Tabriz University of Medical Sciences (47.5\%) (20), and hospitals of Shiraz University of Medical Sciences (SUMS) (67.5\%) (21).Most work engagement concepts studied in nursing literature are pertinent to models of empowerment and areas of work life. Empowerment is highly influenced by structural elements within the organization. An empowering work environment ensures that employees have access to information, resources, support and opportunities to learn and grow. For instance, it was demonstrated that structural empowerment had an indirect negative effect on nursing emotional exhaustion through six areas of nursing work life, namely, workload, control, reward, fairness, community and values (22). The same study revealed that leader empowering behavior had an indirect effect on nursing engagement through structural empowerment and six areas of nursing work life (23).

Literature review shows that there are few studies investigating the relationship between work engagement and its related variables. It has been shown that job satisfaction significantly moderated the relationship between work engagement of nurses and their inclination to quit working (12). It has been implied that facilitators and barriers of nursing engagement centered around six areas of organizational work life (workload, control, reward, fairness, community, and values) revealing that values fostering nurse engagement can lead to more positive work experiences and, subsequently, a greater sense of well-being (14). It has been demonstrated that improving work engagement has enhanced sense of belonging, teamwork and positive work relationships among older nurses (24) as well as social interaction between patients and nurses with subsequent impact on nurses' practice (25). Another study revealed significant relationships between work engagement and its effective factors among nurses (26).In fact, other professions have examined models and measurements of work engagement more extensively than nursing $(27,28)$. However, what induces engagement among nurses and what the consequences are have not been probed yet; although, a plethora of studies have explicitly investigated antecedents and consequences of work engagement in a variety of other professions $(7,9,29)$.Having considered the above-mentioned global deficiencies in nursing work engagement inquiry, the present study attempted to determine antecedences and consequences of work engagement among nurses in the teaching hospital of Shiraz University of Medical Sciences (SUMS), Shiraz, Iran,, by means of a modified version of Saks's model (11). Findings can potentially reduce nursing burnout at least in the region and operate as initiatives for other studies aimed to improve quality of universal nursing services. The model used in the present study was that of Saks (2006), which is basically based on the engagement models of both Kahn (1990) and Maslach et al. (2001) as well as Social Exchange Theory (SET) $(2,11$, 30). SET argues that "obligations are generated through a series of interactions between parties who are in a state of reciprocal interdependence" (11). It provides a theoretical foundation to explain why employees choose to become more or less engaged in their work. Saks' model introduces work engagement with respect to its antecedents and consequences. According to Saks (2006), the antecedents of work engagements are job characteristics, rewards and recognition, supervisory-organizational support, and organizational justice. The consequences consist of job satisfaction, organizational commitment, Organizational Citizenship Behavior (OCB), and absence of intent to quit the organization (11). His model was the most comprehensive one to date investigating nurses' engagement at work due to variety of factors considered to be related to nursing performance in a workplace. In the current study, due to lack of empirical research on factors predicting work engagement, four antecedents from Saks' model were selected as potential predictors of work engagement among nurses. These items include job characteristics, rewards and recognition, and organizational and supervisory support. However, in our hypothesized model organizational justice, which is one of the antecedents of Saks's model was excluded. These antecedents are briefly defined as follows: 1) Job characteristics: it is based on Hackman and Oldham's (1980) job characteristics model, which includes five core elements namely, skill variety, task identity, task significance, autonomy, and feedback (31).2) Rewards and recognition: as argued by Kahn (1990), employees receiving a greater amount of rewards and recognition for their role performances would probably be engaged more at work (2).3) Organizational and supervisory support: supportive environments can allow workforce to experience novelties or even failure without fear of consequences (11). The consequences of work engagement in our hypothesized model included job satisfaction, Organizational Citizenship Behavior (OCB) (OCB has been defined as "individual behavior that is discretionary, not directly or explicitly recognized by the formal reward system, and that in the aggregate, promotes the effective functioning of the organization" (32)), and absence of intention to quit, which were the same as those of the Saks' model. Considering these three items as the consequences of work engagement means that work engagement potentially leads to both individual and organizational-level outcomes (33). As engaged employees are more satisfied with their jobs, they have a greater attachment to their organization irre- 
spective of the formal reward system and, consequently, a lower intention to leave the job (9).

\section{Objectives}

The present study considered three objectives, which are basically pertinent to the context of the study, as follows: 1) identifying a suitable work engagement model, 2) determining antecedents related to work engagement, and, finally, 3) determining consequences related to work engagement.

\section{Patients and Methods}

This was a quantitative cross-sectional study. Hospitals under study were chosen from general hospitals of SUMS (According to the definition presented by the Iranian Ministry of Health, a general hospital is defined as a hospital which includes at least four active inpatient wards of internal, surgery, gynecology, and pediatrics as well as having the departments of laboratory, pharmacy, emergency, and nutrition(34)) in Shiraz, Iran, during winter 2011. Because these hospitals are usually larger with more active inpatient wards compared to private ones, and consequently, more nurses can take part in the study. Only two Namazi and Faghihi hospitals (with bed numbers of 370 and 612, respectively) affiliated with SUMS met the criteria. Nurses working in different inpatient wards of these two hospitals constituted the research population.

\subsection{The Instrument}

The instrument of the study was a questionnaire consisting of 123 questions. Study variables were measured by some related items in the questionnaire. Work engagement was measured with the Utrecht Work Engagement Scale (UWES) (35). The UWES includes 17 items indicative of three dimensions, namely 'vigor' (six items, e.g. 'At work, I feel full of energy'), 'dedication' (five items, e.g. 'I am enthusiastic about my job') and 'absorption' (six items, e.g. 'When I am working, I forget everything else around me'). Supervisory and organizational support was measured with eighteen items covering supervisory and organizational dimensions. Examples are 'My supervisor provides me with ongoing feedback' and 'our organization places much value on employee learning and development activities' (36). Organizational citizenship behavior (OCB) was measured with 14 items. A sample item was 'Sometimes nurses do activities beyond their formal duties which can enhance the outside image of the organization' (36). Job characteristics were measured by six items from Hackman and Oldham (1980) with each item corresponding to a core job characteristic (autonomy, task identity, skill variety, task significance, feedback from others, and feedback from the job) (31). Job satisfaction was measured using the index of work satisfaction (IWS) (37) with thirty-seven items. An example item was 'I am satisfied with the types of activities I do in my job'. The above-mentioned five variables were scored on a fivepoint Likert scale ('totally disagree' $=1$ to 'totally agree' = 5). Intent to leave was measured with one item on fivepoint scale ranging from 'definitely will not leave' $=1$ to 'definitely will leave' $=5$. The item was' Which of the following statements most clearly reflects your feelings about your future in the organization?' (37) Rewards and recognition included ten items such as, 'payment raise' measured by six-point scale ['I don't get anything' $=1$, to 'a large extent' =6]. Translation validity of the questionnaire was established by translating all scales firstly into Persian (forward translation) and then into English (backward translation) by an applied linguist. The translated version was observed by a field specialist and finally approved after necessary changes. To determine the content validity of the questionnaire, the final translated version was given to four experts with specialties of health services management, organizational behavior, and nursing. The researcher applied their advices and the new modified version of the questionnaire was again sent to the experts to confirm the changes. To estimate the reliability scale across all subscales, 30 questionnaires were distributed among nurses in Faghihi Hospital. The Cronbach's alpha reliability coefficients for all variables of the questionnaire were between 0.8 and 0.9 (Table 1). These 30 completed questionnaires were then included in thedata obtained from Faghihi Hospital.

\begin{tabular}{|c|c|c|c|c|c|c|}
\hline \multirow[t]{2}{*}{ Scale } & \multirow[t]{2}{*}{ Cronbach $\alpha$} & \multirow[t]{2}{*}{ Mean \pm SD } & \multirow[t]{2}{*}{ Variables } & \multicolumn{3}{|c|}{ Effects $(\beta)$} \\
\hline & & & & Indirect & Direct & Total \\
\hline WE & 0.88 & $58.95 \pm 10.51$ & R\&R on JS & 0.026 & 0.31 & 0.336 \\
\hline oss & 0.8 & $59.35 \pm 11.24$ & JC-OCB & 0.019 & 0.32 & 0.339 \\
\hline JC & 0.84 & $19.46 \pm 4.07$ & R \& R-JS, IL, OCB & 0.351 & & \\
\hline R\&R & 0.9 & $107.47 \pm 13.33$ & OSS-JS, IL, OCB & 0.130 & & \\
\hline \multirow[t]{2}{*}{ OCB } & 0.83 & $56.5 \pm 8.21$ & JC-JS, IL, OCB & 0.099 & & \\
\hline & JS & $0.84 \pm 107.47$ & 13.33 & & & \\
\hline IL & - & $2.92 \pm 1.22$ & & & & \\
\hline
\end{tabular}

\footnotetext{
a Abbreviations: WE, work engagement; OSS, Organizational- supervisory support; JC, Job characteristics; R\&R, reward and recognition; OCB,
} Organizational citizenship behavior; JS, Job satisfaction; IL, Intention to leave. 


\subsection{Data Collection}

Nurses working in these two hospitals with following features were included in the study: 1) having at least bachelor's degree in their own field, 2) having at least one subsequent year of experience in in-patient wards, and, 3) working only in hospitals under study. The only exclusion criterion was those nurses who had left any inpatient ward of either hospital during data collection. From 954 nurses (338 and 616 in Faghihi and Namazi hospitals, respectively) included in the study based on the mentioned criteria (with no excluded cases), 300 nurses were selected using simple random sampling. Of these samples, 100 nurses were working in Faghihi hospital and 200 in Namazi hospital.

All nurses received an envelope containing a questionnaire, a blank piece of paper to insert their suggestions/ criticisms and a pen. This package was supposed to facilitate completing the questionnaire and returning it even when the nurses were at work. Questionnaires were accompanied by a letter in which the goal of study was briefly introduced and the confidentiality and anonymity of the answers were emphasized. Sufficient time to complete the questionnaire was considered 15 minutes. A student was hired to contact respondents to make sure they would fill and return the questionnaires. Nurses were allowed to fill the questionnaires at anytime or anywhere they felt comfortable. Twenty-one questionnaires were not returned. Finally, 279 questionnaires were retrieved (95 from Faghihi and 184 from Namazi) with the return rate of $93 \%$. This number of participants appeared to be adequate since in Structural Equation Modeling (SEM), two different numbers for adequate sample size were suggested: more than 100 (38) and more than 200 people $(39,40)$. Data collection took eight months.

\subsection{Data Analysis}

To illustrate the features of participants as well as frequency distribution of the study variables, descriptive statistics was conducted by means of SPSS (version 11, SPSS Ink, USA ). To examine the model, LISREL 8.53 was found to be suitable to conduct SEM in this study. To replace the existing missing values in our data, we applied Pairwise technique, which is usually used for multivariate techniques such as SEM. The model equation used in the study was: $\mathrm{y}=\mathrm{By}+\square \mathrm{x}+\mathrm{u}$ where $\mathrm{y}=\left(\mathrm{y}_{1}, \mathrm{y}_{2}, \ldots, \mathrm{y}_{\mathrm{p}}\right)$, which is a set of jointly dependent variables, $\mathrm{x}=\left(\mathrm{x}_{1}, \mathrm{x}_{2}, \ldots, \mathrm{x}_{\mathrm{q}}\right)$ is a set of predetermined variables uncorrelated with the error terms $\mathrm{u}=\left(\mathrm{u}_{1}, \mathrm{u}_{2}, \ldots, \mathrm{u}_{\mathrm{p}}\right), \mathrm{B}$ and $\square$ are parameter matrices (41). Each of the model components was included as a factor observed by the scales of the questionnaire. Several commonly-fit indices including Chi-Square, the Root Mean Square Error-of-Approximation (RMSEA), the Adjusted Goodness-of-Fit Index (AGFI), the Comparative Fit Index (CFI), and Hoelter index were applied to test the fitness of our hypothesized model. For Chi-Square, lower values are desirable (42) while for AGFI and CFI values of 0.90 or higher (43) and for RMSEA values lower than 0.08 (42) are commonly acceptable. The Hoelter index is usually calculated to find out if Chi-Squareis significant. If its value is more than 200 for the model, then the model is considered a good fit with observed data (44).

LISREL Project, a causal modeling technique, was used to test the theoretical model presented in Figure 1, the level of significance chosen for this study was 0.05 .

\subsection{Ethical Considerations}

The Vice-Chancellery for Research and Technology of the University and the ethics committee approved the study. Besides, permission was obtained from the Institutional Review Board (IRB) of Namazi and Faghihi hospitals to distribute the questionnaires.Confidentiality of personal information and informed consent were considered in this study.

\section{Results}

In total, 279 participants aged 22-51 years $(M=31.9, S D=$ 7.2), mostly between $22-28$ years (37.3\%). They had an average of $9.25 \pm 7.21$ years of experience in nursing and had spent an average of $8 \pm 6.7$ years in their own institutions. Other demographic information of participants were presented in Table 2.

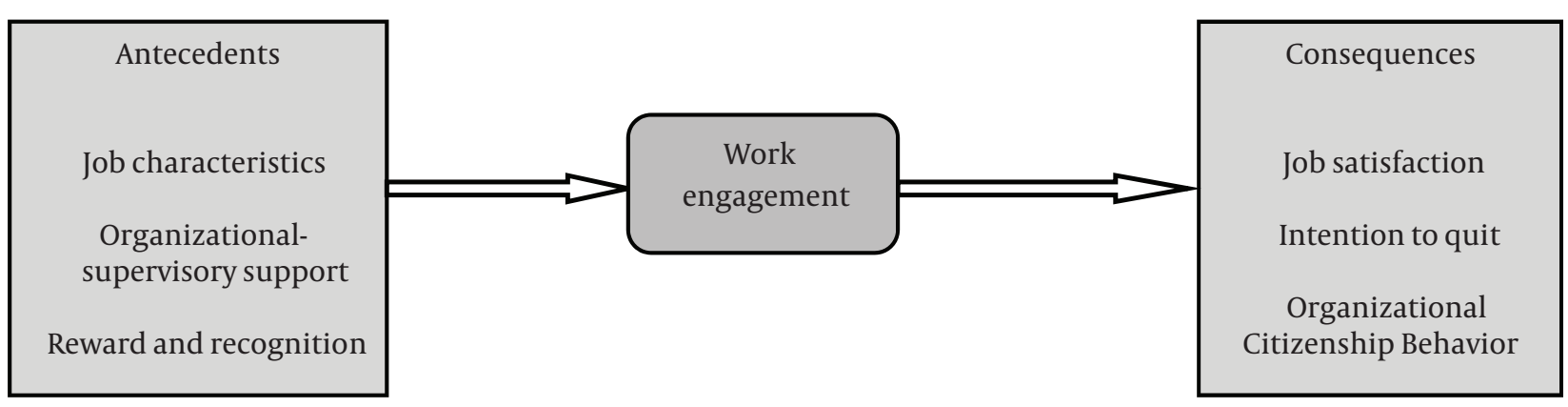

Figure 1. The Initial Model of the Antecedents and Consequences of Work Engagement 
Table 2. Demographic Data of Participants ${ }^{a}$

\begin{tabular}{|lcc}
\hline & Frequency & $\begin{array}{c}\text { Nursing Experiences } \\
\text { by Age }\end{array}$ \\
\hline Age & $104(37.3)$ & $3.18 \pm 2.6$ \\
\hline $22-28$ & $97(34.8)$ & $8.62 \pm 4.5$ \\
\hline $28-34$ & $42(15.1)$ & $12.37 \pm 4.3$ \\
\hline $34-40$ & $28(10)$ & $14.47 \pm 5.7$ \\
\hline $40-46$ & $8(2.9)$ & $18.13 \pm 9.5$ \\
\hline Over 46 & $18(6.5)$ & \\
\hline Gender & $261(93.5)$ & \\
\hline Male & & \\
\hline Female & $139(49.8)$ & \\
\hline Marriage status & $138(49.5)$ & \\
\hline Single & $2(0.7)$ & \\
\hline Married & & \\
\hline Others & & \\
\hline Educational level & & \\
\hline Bachelor degree & $271(97.1)$ & \\
\hline Master degree & $8(2.9)$ & \\
\hline Organizational & & \\
\hline position & & \\
\hline Staff nurse & & \\
\hline Head nurse & & \\
\hline Employment status & & \\
\hline Tenured & & \\
\hline Other & & \\
\hline Datractual & & \\
\hline
\end{tabular}

a Data are presented as Mean \pm SD or No. (\%).
Normal distribution of data was confirmed using Kolmogorov-Smirnov distribution test before data analysis. The initial hypothesized model did not meet the criteria for a good fit in SEM analysis using maximum likelihood estimation $(\chi 2=101.3$, AGFI $=0.82$, CFI $=0.85$, RMSEA $=$ 0.13 ), but all structural coefficients were statistically significant (Figure 2).

The modification indices suggested two additional theoretically defensible paths among work engagement and its antecedents and consequences. These paths were added to the model to test their impacts. The first path was added from reward and recognition as an independent variable to job satisfaction as a dependent variable $\left(\chi^{2}=\right.$ 67.10$, AGFI $=0.87$, CFI $=0.90$, RMSEA $=0.136)$. The second path was made as a connection between job characteristics as an independent variable and OCB as a dependent variable. Variables of the two new paths showed significant relationships as well $(t=6.78$ for job satisfaction and rewards and recognition, $\mathrm{t}=6.85$ for job characteristics and OCB).This final model revealed a good fit $\left(\chi^{2}=23.62\right.$, AGFI $=0.93$, CFI $=0.97$, RMSEA $=0.07$ ) (Figure 3 ). In our study, the Hoelter index was 372 (at 0.05 level) for the hypothesized model suggesting that Chi-Square value of our model is significant. These results were related to the first objective of the study confirming that the hypothesized model was identified to be suitable to explain work engagement in nursing profession.

In Table 1, all effects of the model variables were demonstrated showing that reward and recognition had both direct and indirect effects on job satisfaction. The same dual effects occurred between job characteristics and organizational citizenship behavior. However, supervisoryorganizational support showed only indirect effects on the consequences. In this enhanced model fit, all coefficients were found to be significant. Work engagement was significantly related to supervisory and organizational support $(t=3.1)$, job characteristics $(t=2.07)$, rewards and recognition $(t=2.8)$ as its antecedents and job

Figure 2. Results of Initial LISREL Analyses With Standard Path Coefficients

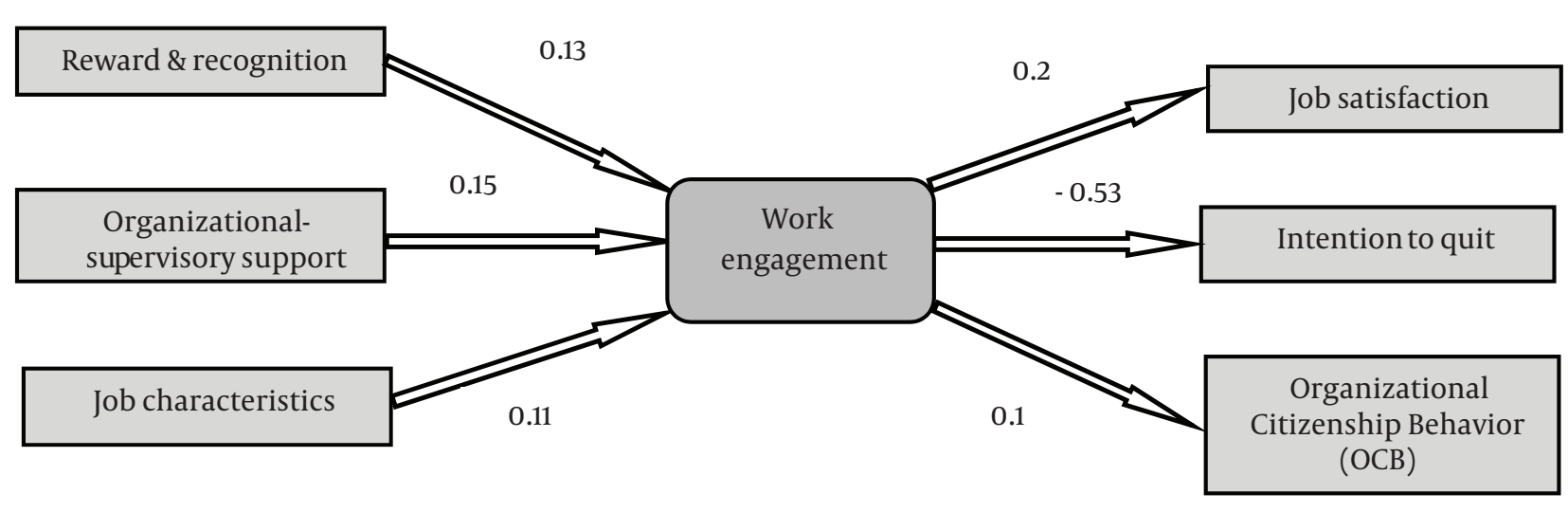

Chi-Square $=101.03 ;$ P Value $=0.000 ;$ RMSEA $=0.13 ; \mathrm{df}=12$ 
0.31

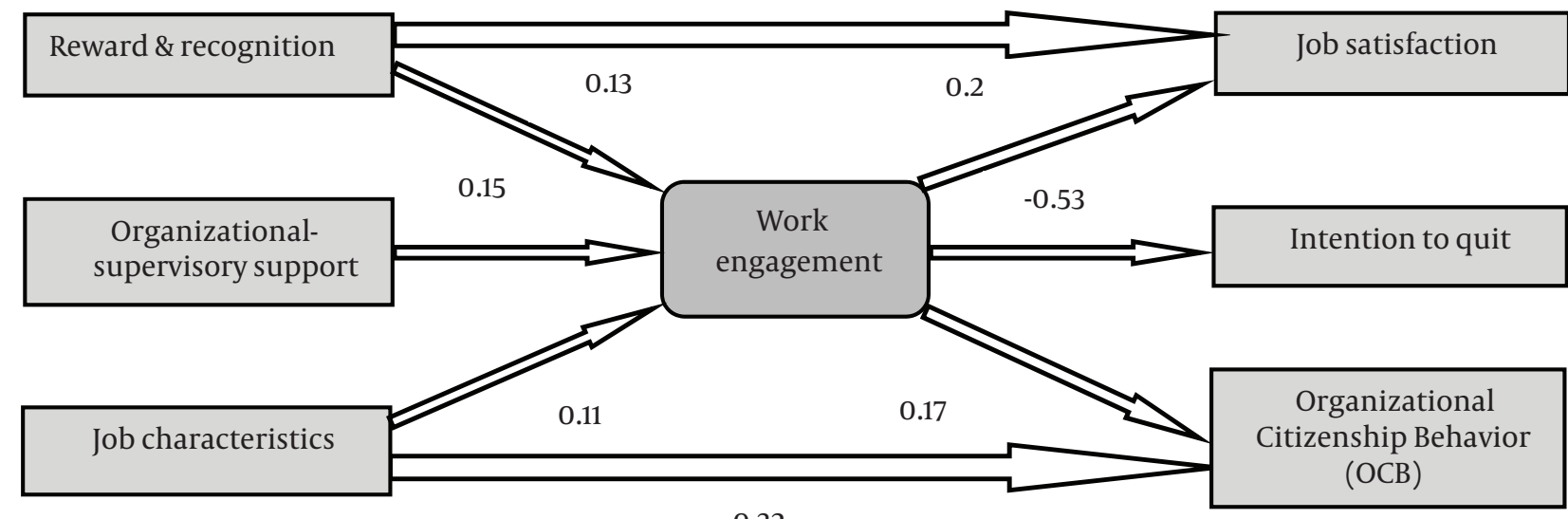

0.32

Chi-Square $=23.62 ;$ P Value $=0.00868 ;$ RMSEA $=0.070 ; \mathrm{df}=10$

satisfaction $(t=11.61)$, intent to leave $(t=-11.72)$, and OCB $(t=11.59, P<0.05)$ as its consequences. These results were pertinent to the second and third objectives of our study. As seen in Figure 3, all coefficients of the model paths in standard estimation were significant.

\section{Discussion}

Our findings regarding antecedents and consequences of work engagement among nurses working at teaching hospitals of SUMS indicate that supervisory and organizational support, rewards and recognition, and job characteristics are related to work engagement as its antecedents. The consequences of work engagement, on the other hand, are seen as job satisfaction, intent to leave (as a negative outcome), and OCB. Additionally, as the final analysis of the model showed, two new paths were added to the model. According to the findings, rewards affect the model in two dimensions: firstly, on work engagement as one of the antecedents, and secondly, on nursing job satisfaction, which is actually the first new relation, emerged from the data (Figure 3). A model, tested by Laschinger and Wong (2006) showed a similar relationship between work engagement of nurses and their rewards (45). Although Laschinger and Leiter's study (2009) suggested a similar relationship (46), what makes our finding different is the emergence of new connection between rewards and job satisfaction of nurses. This may imply that rewards and recognition play an important role in both job satisfaction and engagement of nurses working in developing countries, like Iran, but it could not be generalized for nurses in developed countries like Canada.

Emergence of the above-mentioned path shows that reward and recognition directly lead to job satisfaction among nurses. It seems that this strong relationship be- tween reward and job satisfaction is indicative of the importance of reward on inducing nurses' positive attitudes toward their jobs, which can develop their satisfaction of delivering services to patients as well as their other key responsibilities. Based on the results of the present study, there is a relationship between work engagement and job characteristics (i.e. skill variety, task identity, task significance, autonomy, and feedback) as its antecedent. The second new path, emerged from the data analysis, showed an unexpected direct relationship between job characteristics and OCB (Figure 3). This may explain that establishing general five job characteristics in a hospital may induce more feeling of belonging to organizations among nurses. Although no previously published study examined direct effect of job characteristics of nurses on their work engagement and OCB, some authors demonstrated the relation of feedback and autonomy (as two elements of job characteristics) with work engagement among electronic engineers, police officer, and teachers (27, 28, 47). Job satisfaction, $\mathrm{OCB}$, and intent to leave were the outcomes of work engagement behavior in accordance with Saks' findings. The strong relationship between work engagement and job satisfaction in our study was highlighted by some authors $(28,46,48)$. This finding suggests that engaged nurses are more interested in their jobs, apparently show more tendency to stay in their job positions, and have more inclination to perform activities beyond their job descriptions. These positive states of mind can potentially bring about beneficial outcomes for the hospitals. The negative relationship between work engagement and absence of intend to leave in the present study (Figure 3) was shown by some authors $(46,48,49)$. It seems that engaged nurses are more motivated to stay in hospitals and work more efficiently, which leads to good patient care and work life improvement. Several limitations were present in this study. One limitation was about the questionnaire 
as the major tool for data gathering. As nursing profession deals with highly laborious tasks, some nurses may not have answered the questions with adequate amount of attention and peace of mind. Another limitation related to our theoretical model was the possibility of ignoring potential variables affecting nurses' work engagement. The findings of the present study can be applied to reduce burnout among Iranian nurses through establishing related antecedents of work engagement to enjoy its consequences. To achieve this goal, managers are required to observe the elements of job characteristics mentioned above, offer greater amount of rewards and recognition for the nurses' performances, and finally, provide a supportive environment for them. It is likely that the resulted work engagement among nurses produces the abovementioned consequences namely, job satisfaction, sympathetic OCB, and reduction of turnover. This favorable patient care quality can bring about both financial and non-financial benefits for hospitals, and consequently, for overall health system of the country. The findings can also operate as initiatives for other studies in a variety of world contexts to improve the quality of global nursing services. A study conducted in Namazi teaching hospital of SUMS reported a high rate of job burnout among nurses (75.5\%), which influenced their efficiency to provide care to patients (50). The model developed in the current study was resulted from local nurses of the same hospital. Therefore, it is suggested to consider the model by health managers to help reduce burnout. Finally, it is suggested to perform national survey in work engagement and its antecedences and consequences among medical doctors, health managers, and other health professions. Additionally, it is required to identify other probable antecedents and consequences of nursing work engagement, which might be related to specific cultural settings.

\section{Acknowledgements}

The authors gratefully acknowledge the feedbacks provided by Dr. Arian Gholipour, the faculty member of Tehran University, and Dr. Zahra Kavosi, the faculty member of Shiraz University of Medical sciences.

\section{Authors'Contributions}

Study concept and design, acquisition of data, analysis and interpretation of data and statistical analysis: Sohrabizadeh; Critical revision of the manuscript for important intellectual content, administrative, technical, and material support and study supervision: Sayfouri; Drafting of the manuscript: Sohrabizadeh and Sayfouri.

\section{Funding/Support}

This study was supported by both Shiraz University of Medical Sciences, Shiraz, Iran and Iran University of Medical Sciences, Tehran, Iran.

\section{References}

1. Hakanen JJ, Perhoniemi R, Toppinen Tanner S. Positive gain spirals at work: From job resources to work engagement, personal initiative and work-unit innovativeness. J Vocat Behav. 2008;73(1):78-91.

2. Kahn WA. Psychological conditions of personal engagement and disengagement at work. Acad Manag J.1990;33(4):692-724.

3. Cameron IL, Munoz J, Barnes CJ, Hardman WE. High dietary level of synthetic vitamin E on lipid peroxidation, membrane fatty acid composition and cytotoxicity in breast cancer xenograft and in mouse host tissue. Cancer Cell Int. 2003;3(1):3.

4. Wright TA. Positive organizational behavior: An idea whose time has truly come.J Organ Behav. 2003;24(4):437-42.

5. Bakker AB, Demerouti E. Towards a model of work engagement. Career Dev Int. 2008;13(3):209-23.

6. Schaufeli WB, Salanova M, Gonzalez-Roma V, Bakker AB. The measurement of engagement and burnout: A two sample confirmatory factor analytic approach.J Happiness Stud. 2002;3(1):71-92.

7. Koyuncu M, Burke RJ, Fiksenbaum L. Work engagement among women managers and professionals in a Turkish bank: Potential antecedents and consequences. Equal Oppor Int. 2006; 25(4):299-310.

8. Richardsen AM, Burke RJ, Martinussen M. Work and health outcomes among police officers: The mediating role of police cynicism and engagement. Int J Stress Manag. 2006;13(4):555.

9. Schaufeli WB, Bakker AB. Job demands, job resources, and their relationship with burnout and engagement: A multi - sample study.J Organ Behavior. 2004;25(3):293-315.

10. Salanova M, Agut S, Peiro JM. Linking organizational resources and work engagement to employee performance and customer loyalty: the mediation of service climate. J Appl Psychol. 2005;90(6):1217-27.

11. Saks AM. Antecedents and consequences of employee engagement. J Manage Psychol. 2006;21(7):600-19.

12. Simpson MR. Engagement at work: A review of the literature. Int J Nurs Stud. 2009;46(7):1012-24.

13. Spence Laschinger HK, Leiter MP. The impact of nursing work environments on patient safety outcomes: the mediating role of burnout/engagement. J Nurs Adm. 2006;36(5):259-67.

14. Ozer EJ, Weinstein RS, Maslach C, Siegel D. Adolescent AIDS prevention in context: the impact of peer educator qualities and classroom environments on intervention efficacy. Am J Community Psychol.1997;25(3):289-323.

15. Freeney YM, Tiernan J. Exploration of the facilitators of and barriers to work engagement in nursing. Int $J$ Nurs Stud. 2009;46(12):1557-65.

16. Aziznezhad P, Hosseini J. Job burnout and its antecedents among clinical nurses worked in Babol University of Medical Sciences hospitals. Sci Med J Birjand Univ Med Sci. 2006;8(2):63-9.

17. Khajedin N, Hakimshushtari M, Hajebi A. Job burnout syndrome in relation with control center comprehend of nurses in psychological hospital, Tehran. J Clin Psychol Iran. 2006;12(1):43-8.

18. Shakerinia E, Mohammadpour M. Relation of job burnout with stress and resilience among female nurses. Behbud J. 2010;14(2):161-9.

19. Yaghubinia F, Mazlum R, Salehi J, Esmaeeli H. Relationship between self-esteem and job burnout among nurses of Mashhad University of Medical Sciences. Asrar J. 2004;10(3):73-9.

20. Rahmani F, Behshid M, Zamanzadeh V, Rahmani F. Relationship between general health, occupational stress and burnout in critical care nurses of Tabriz teaching hospitals. Iran J Nurs. 2010;23(66):54-63.

21. Moghadam NJ, Soleimani S. Burnout and its relationship with social support of nursing in hospitals of Shiraz University of Medical Sciences. Sadra Med Sci J . 2013;1(2):69-76.

22. Sarmiento TP, Laschinger HK, Iwasiw C. Nurse educators' workplace empowerment, burnout, and job satisfaction: testing Kanter's theory. J Adv Nurs. 2004;46(2):134-43.

23. Cho J, Laschinger HK, Wong C. Workplace empowerment, work engagement and organizational commitment of new graduate nurses. Nurs Leadersh (Tor Ont). 2006;19(3):43-60. 
24. Bishop M. Work engagement of older registered nurses: the impact of a caring-based intervention. J Nurs Manag. 2013; 21(7):9419.

25. Stoddart KM. Social meanings and understandings in patientnurse interaction in the community practice setting: a grounded theory study. BMC Nurs. 2012;11:14.

26. Keshtkaran A, Kavosi Z, Gholipour A, Sohrabizadeh S, Sharafi Z. Work Engagement \& Effective Factors Among Nurses In General Teaching Hospital Of Shiraz University Of Medical Sciences. Payavard Salamat. 2012;6(1):147-56.

27. Hakanen JJ, Bakker AB, Schaufeli WB. Burnout and work engagement among teachers. J Sch Psychol. 2006;43(6):495-513.

28. Bakker AB, van Emmerik H, Euwema MC. Crossover of burnout and engagement in work teams. Work Occup. 2006;33(4):464-89.

29. Maslach C, Schaufeli WB, Leiter MP. Job burnout. Annu Rev Psychol.2001;52:397-422.

30. May DR, Gilson RL, Harter LM. The psychological conditions of meaningfulness, safety and availability and the engagement of the human spirit at work. J Occup Organ Psychol. 2004;77(1):11-37.

31. Hackman JR, Oldham GR. Work redesign.The University of Michigan: Addison-Wesley; 1980.

32. Organ DW. Personality and organizational citizenship behavior. $J$ Manag. 1994;20(2):465-78.

33. Kahn WA. To be fully there: Psychological presence at work. Hum Relations. 1992;45(4):321-49.

34. Ministry of Health Guideline.. Words and Definitions . 2014. Available from: http://treatment.tbzmed.ac.ir/uploads/30/CMS/user/ file/47/aennameh/140.pdf.

35. Schaufeli WB, Bakker AB, Salanova M. The measurement of work engagement with a short questionnaire a cross-national study. Educ Psychol Meas. 2006;66(4):701-16.

36. Qiumei XU. A predictive Model of Employee SelfDevelopment.Irvine: University of California; 2007.

37. Keller JL, Unger MS. Exploring a Model of Skillful Engagement in
Nursing Practice.: The University of Texas Health Sciences Cente; 2008.

38. Bollen KA. Structural equations with latent variables.New York: Wiley Online Library; 1989.

39. Williams B, Brown T, Onsman A. Exploratory factor analysis: A five-step guide for novices. Australas J Paramedicine. 2012;8(3):1.

40. Schumacker RE, Lomax RG. A beginners guide to structural equation modeling.Mahwah: Laurence Erlbaum;1996.

41. Toit Sd, Toit Md, Joreskog KG, Sorbom D. Interactive LISREL: User's Guide.Chicago: Scientific Software International; 1999.

42. MacCallum RC, Browne MW, Sugawara HM. Power analysis and determination of sample size for covariance structure modeling. Psychol Methods. 1996;1(2):130.

43. Hoyle RH. Structural equation modeling: Concepts, issues, and applications.: Sage Publications; 1995.

44. Jain TK, Sharma A. Service Quality Model: Model Fit Indices Results. Int J Engin ResTechnol. 2012;1(10).

45. Laschinger HK, Wong CA, Greco P. The impact of staff nurse empowerment on person-job fit and work engagement/burnout. Nurs Adm Q. 2006;30(4):358-67.

46. Spence Laschinger HK, Leiter M, Day A, Gilin D. Workplace empowerment, incivility, and burnout: impact on staff nurse recruitment and retention outcomes. J Nurs Manag. 2009;17(3):302-11.

47. Xanthopoulou D, Bakker AB, Demerouti E, Schaufeli WB. Reciprocal relationships between job resources, personal resources, and work engagement. J Vocat Behavior. 2009;74(3):235-44.

48. Louison CP. Convergent And Discriminant Validity of Employee Engagement.San Diego: Alliant International University; 2007.

49. Du Plooy J, Roodt G. Work engagement, burnout and related constructs as predictors of turnover intentions: original research. $J$ Ind Psychol. 2010;36(1):1-13.

50. Oji KA, Shafaghat A. Constituents and antimicrobial activity of the essential oils from flower, leaf and stem of Helichrysum armenium. Nat Prod Commun. 2012;7(5):671-4. 